[Agr. Biol. Chem., Vol. 30, No. 4, p. 406 415, 1966]

\title{
Studies on the Polyuronide of Oh-gyo-tye (The Achine of Ficus awkeotsang MAKINO)
}

\author{
Part I. On the Chemical Structure of the Polyuronide
}

\author{
By Yoshiaki Oda and Ryutaro TANAKA* \\ Laboratory of Biochemistry, Department of Agricultural Chemistry, College of \\ Agriculture, University of Osaka Prefecture \\ Received October 21, 1965
}

\begin{abstract}
A polyuronide, main component of the water extract of achine of Ficus awkeotsang MAKINo (on-gyo-tye), was purified by ion-exchange chromatography on DEAE-cellulose. The polyuronide (Fraction IB) is homogeneous electrophoretically and consists mainly of galacturonic acid. Optical rotation of Fraction IB is $[\alpha]_{D}^{26}=+294.7$ and content of methoxyl group is trace. In periodate oxidation of Fraction IB, molar ratio of galacturonic acid residue and periodate consumption was 1 , and formic acid formation was very small. Periodate oxidation product of Fraction IB was oxidized further with bromine and the resulted substance was hydrolyzed. In the hydrolyzate, presence of large amount of tartaric and glyoxylic acids and small amount of tartronic acid were detected by paper chromatography. Reduced viscosity of aquous solution of Fraction IB increased with decreasing of the concentration of Fraction IB solution. From these results, it was deduced that Fraction IB has a linear structure of $1 \rightarrow 4$ linkage of D-galacturonic acid, probably $\alpha$-linkage.
\end{abstract}

\section{INTRODUCTION}

An achine of Ficus arekeotsang MAKINo, which grows on the mountain sides in the southern and the middle parts of Formosa, is known under the name of "oh-gyo-tye" or "oh-gyo", and the dried achine yields a gelatinous matter when it is sorked in water. This supplies a peculiar jelly cake with addition of sugar, which is called "awkeotsang"

On the studies of this gelatinous matter, Ôno $^{1\rangle}$ deduced from the yield of carbon dioxide evolved by Tollens and Lefévre's method $^{2)}$ that it consists of uronic acid, and identified galacturonic acid as hydrazone derivatives in the hydrolyzate of the matter. In his studies, however, homogeneity of the

\footnotetext{
* Present address, Government Industrial Research Institute, Osaka.

1) S. Ono, Bull. School Agr. For. Taihoku Imp. Univ., 1, 1 (1940).

2) B. Tollens and K. U. Lefévre, Ber., 40, 4513 (1907).
}

sample was not tested and detection of any other components was not attempted.

Authors obtained a polyuronide which was main component. In the present paper, purification, detection of components, and results of periodate oxidation and viscosity measurement were described. From the results a possible structure of the polyuronide was proposed.

\section{MATERIAL AND METHODS \\ 1. Material \\ Oh-gyo-tye, a production in formosa, had been stored in our laboratory for several years, and it was used for preparation of the present polyuronide.}

\section{Electrophoresis}

Hitachi Tiselius Apparatus HTB-2 was used for electrophoretic experiments.

3. Chromatography

i) Thin-layer chromatography. Glass plate was 
coated with suspension containing $30 \mathrm{~g}$. of Silica gel $\mathrm{G}$ (E. Merk AG, Darmstadt, Germany) in $60 \mathrm{ml}$. of boric acid solution to a thickness of $0.2 \mathrm{~mm}$. The adsorbent was activated at $85^{\circ} \mathrm{C}$ for half an hour, after drying at room temperature for forty five minutes. Sample was applied on the activated plate and was developed in a mixture of benzene-acetic acid-methanol $(1: 1: 3)$ at room temperature.

ii) Paper chromatography. One-way ascending chromatography on Toyo Roshi No. 52 paper was carried out using $n$-butanol-acetic acid-water $(4: 1: 1)$ as solvent.

\section{Analysis}

Uronic acid was detected by Dische's test. ${ }^{3}$ Periodate and formic acid were determined by Fleury and Lange's method, 4 and Whistler and Hickson's method, $\left.{ }^{5}\right)$ respectively. Nelson's method ${ }^{6}$ ) was applied for measurement of reducing activity. Methoxyl group was determined by the method of Sofue et al, ${ }^{7}$ which depends upon the colorimetric assay at $365 \mathrm{~m} \mu$ of methyl iodide-pyridinium salt forming in pyridine by Kirpal and Bühn's method.8)

\section{Measurement of optical rotation}

The sample was dried in vacuo over silica gel at $60^{\circ} \mathrm{C}$ overnight, and a known amount of it was dissolved in water. On the solution, optical rotation was measured by Yanagimoto Autorecording-Polarimeter OR-1.

\section{Measurement of viscosity}

Viscosity measurement was carried out at $35^{\circ} \pm$ $0.01^{\circ}$ using a Fitz-Simonds' dilution type viscometer.

\section{RESULTS AND DISCUSSION}

\section{Preparation of polyuronide}

i) Pre-treatment. Dried oh-gyo-tye was kept in 95\% alcohol overnight. Meanwhile, the brown color was developed in alcohol. The oh-gyo-tye was then separated from the alcohol by filtration. This procedure was repeated until the color in alcohol became inappreciable. The oh-gyo-tye was finally treated with ether and was dried.

3) Z. Dische, J. Biol. Chem., 167, 189 (1947).

4) P.F. Fleury and J. Lange, J, pharm. chim., [8] 17, 107 196 (1933)

5) R.H. Whistler and J.L. Hickson, J. Am. Chem. Soc., 76, 1617 (1954).

6) N. Nelson, J. Biol. Chem., 153, 375 (1944).

7) H. Sofue, A. Hatano and T. Arai, Sen-i Gakkaishi (Journal of the Society of Fiber Science and Technology, Japan.), 15, 21 (1959).

8) A. Kirpal and T. Bühn, Ber., 47, 1087 (1914). ii) Extraction with water. The pre-treated oh-gyo-tye was put into a bag of cotton cloth. The bag was soaked in 21 . of distilled water, ${ }^{* *}$ and was rubbed and squeezed by hands, so that a gelatinous matter was extracted into water. This procedure was repeated twice. Then 2 volumes of $95 \%$ alcohol were added to the water extract. Gel-like precipitate was formed. The precipitate was collected by filtration through cheese cloth and was dried in vacuo over silica gel at room temperature, after treatment with absolute alcohol and ether, successively. The dried precipitate was suspended in 11 . of water and was adjusted to $\mathrm{pH} 6 \sim 7$ with EDTA-4 Na*** The insoluble matter was removed by filtration. Two volumes of $95 \%$ alcohol was added to this filtrate. Gelatinous precipitate was formed again. The precipitate was collected by filtration through the cheese cloth and was washed with alcohol, repeatedly. The washed precipitate was dried in vacuo over silica gel, after treatment with ether. The dried matter was dissolved in 11 . of water and was dialyzed against water for seventy-two hours, during this period the water was changed three times. A white solid (Fraction I) was obtained by lyophilization of the dialyzate.

iii) Extraction with $0.2 \%$ ammonium oxalate solution. The residue of water extraction was soaked and was extracted in 1.51 . of $0.2 \%$ ammonium oxalate solution with stirring for two hours at room temperature. The suspension was filtered and the residue was reextracted in the same manner. These filtrates were collected and were condensed to $500 \mathrm{ml}$. under reduced pressure at $40^{\circ} \mathrm{C}$. Two volumes of $95 \%$ alcohol were added to this condensed solution. The gelatinous precipitate was collected by filtration through the cheese cloth. Ammonium oxalate, retained in the precipitate, was removed by washing with diluted alcohol (alcohol: water $=2: 1$ ). The washed precipitate

\footnotetext{
* In this work, the water which was distilled with

apparatus of glass, was used in all cases. The abbreviation used anT $A$ ethylenediaminetetra ethylenediaminetetraacetate; diethylaminoethyl cellulose.
} 
was treated with absolute alcohol and ether, successively, and was dried. The dried matter was treated with EDTA-4 Na in the same way as the case of Fraction I. Fraction II was obtained.

iv) Extraction with $0.5 \%$ ammonium oxalate solution. The residue, separated Fraction II, was soaked and extracted in $600 \mathrm{ml}$. of $0.5 \%$ ammonium oxalate solution for two hours at $70^{\circ} \sim 80^{\circ} \mathrm{C}$. The suspension was filtered and the residue was re-extracted under the same condition as above. These extracts were collected and were condensed to about $300 \mathrm{ml}$. under reduced pressure at $40^{\circ} \mathrm{C}$. Two volumes of $95 \%$ alcohol were added to the condensed solution. Gelatinous precipitate was formed. Fraction III was obtained treating the precipitate in the same way as the case of preparation of Fraction II.

v) Extraction with $0.05 \mathrm{~N}$ hydrochloric acid. The residue, separated Fraction III, was soaked and extracted in $600 \mathrm{ml}$. of $0.05 \mathrm{~N}$ hydrochloric acid with stirring for two hours at $70^{\circ} \sim 80^{\circ} \mathrm{C}$. The insoluble matter was removed by filtration. The procedure was repeated twice. These extracts were collected and were condensed to about $300 \mathrm{ml}$. under pressure at $40^{\circ} \mathrm{C}$. Two volumes of $95 \%$ alcohol were added to the condensed solution. Light brown colored precipitate was obtained. The precipitate was collected by filtration and was washed with diluted alcohol (alcohol: water $=$ 2:1) until chloride ion could not be detected. The washed precipitate was treated with absolute alcohol and ether, successively, and was dried. The dried matter was suspended in $100 \mathrm{ml}$. of water and $\mathrm{pH}$ of the suspension was adjusted to $7 \sim 8$ with EDTA- $4 \mathrm{Na}$. Comparing the cases of the preparation of Fraction I, II or III, a large amount of insoluble matter remained in this procedure. The insoluble matter was collected by filtration and was named as Fraction V. The filtrate was treated in the same way as described in the case of preparation of Fraction I, II and III. Fraction IV was obtained.

\section{Yields of each fractions}

Yields of each fractions were shown in Table I. It was appeared that Fraction I was main component of polyuronides of oh-gyotye. Content of methoxyl group in Fraction I was $0.8 \%$. This value was very small compared with the value obtained by Ōno, ${ }^{11}$ $11.8 \%$.

$\begin{array}{lc}\text { TABLE I. YIELD OF EACH } & \text { FRACTIONS } \\ \text { Fractions } & \text { Yield (\%) } \\ \text { Fraction I } & 6 \sim 8 \\ \text { Fraction II } & 1 \sim 2 \\ \text { Fraction III } & 1 \\ \text { Fraction IV } & 0.5 \\ \text { Fraction V } & 0.5\end{array}$

3. Electrophoresis of each fractions

For the electrophoretic analysis, the sample was dissolved in buffer solutions and the solutions were dialyzed against the same buffer solutions for three days before electrophoresis. Electrophoretic patterns of each fractions are shown in Figs. 1 7. Fraction II and III

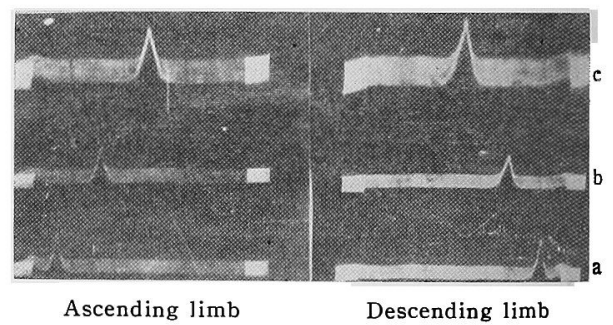

FIG. 1. Electrophoretic Pattern of Fraction I in $1 \%$ Borax Solution.

Time: a, 3000 sec.; b. $5400 \mathrm{sec}$; c, $8960 \mathrm{sec}$. Electric current: $4 \mathrm{~mA}$.

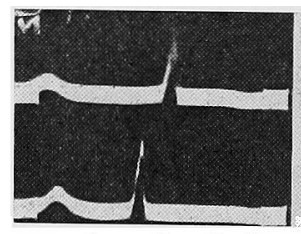

Ascending limb

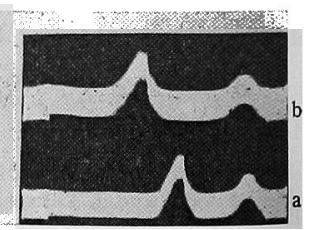

Descending limb
FIG. 2. Electrophoretic Pattern of Fraction I in $0.03 \mathrm{M}$ EDTA Solution ( $\mathrm{pH}$ 9.2).

Time: a, 2400 sec.; b, 3600 sec.

Electric current: $4 \mathrm{~mA}$. 


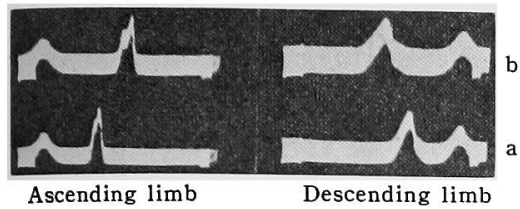

FIG. 3. Electrophoretic Pattern of Fraction I in 0.03 м EDTA Solution ( $\mathrm{pH}$ 6.95).

Time: a, 2100 sec.; b, $3300 \mathrm{sec}$.

Electric current: $4 \mathrm{~mA}$.

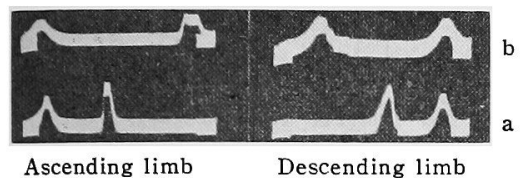

FIG. 4. Electrophoretic Pattern of Fraction I in 0.03 м EDTA Solution ( $\mathrm{pH} 4.6$ ).

Time: a, 1980 sec.; b, $4680 \mathrm{sec}$.

Electric current: $3.6 \mathrm{~mA}$.

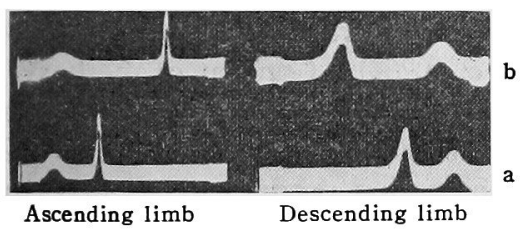

FIG. 5. Electrophoretic Pattern of Fraction II in 0.03 м EDTA Solution ( $\mathrm{pH}$ 6.8).

Time: a, 2100 sec.; b, $3600 \mathrm{sec}$.

Electric current: $3.55 \mathrm{~mA}$

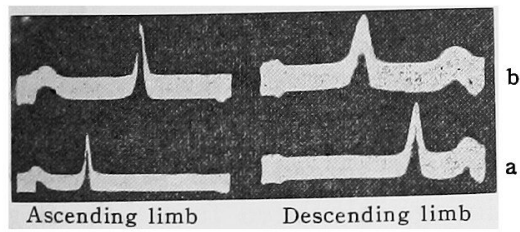

FIG. 6. Electrophoretic Pattern of Fraction III in 0.03 M EDTA Solution ( $\mathrm{pH}$ 6.8).

Time: a, $2100 \mathrm{sec}$; b, $3600 \mathrm{sec}$.

Electric current: $3.55 \mathrm{~mA}$.

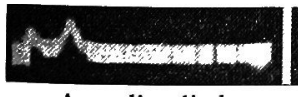

Ascending limb

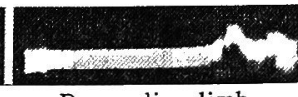

Descending limb
FIG. 7. Electrophoretic Pattern of Fraction IV in 0.03 м EDTA Solution ( $\mathrm{pH}$ 6.8).

Time: 1800 sec.; Electric current: $3.6 \mathrm{~mA}$. showed approximately homogeneous patterns in EDTA solution (Figs. 5 and 6). Though Fraction I is homogeneous electrophoretically in 1\% borax solution (Fig. 1), it shows a heterogeneity in EDTA solution (Figs. 2 4).

\section{Purification of Fraction I}

Since Fraction I contained impurities, it was purified according to the method reported by Heri, Neukom and Deuel ${ }^{9)}$ as below.

Fraction I was dissolved in $0.05 \mathrm{~m}$ sodium phosphate buffer ( $\mathrm{pH} 4.5)$ and was applied to DEAE-cellulose column bufferrized by the same buffer solution ( $1 \mathrm{~g}$. of sample was applied to $100 \mathrm{~g}$. of DEAE-cellulose). The eluate was collected every $40 \mathrm{ml}$. and aliquot of each fractions was used for analysis.

As shown in Fig. 8, Fraction I was separated into several components by this procedure. The component which was not adsorbed on DEAE-cellulose was negative against Devor's test. $^{10)}$ The fraction eluted by linear gradient elution with 0.1 to $0.2 \mathrm{~N}$ sodium hydroxide solution, was main component of Fraction I in Fig. 8. This fraction was named Fraction IB.

Preparation of Fraction IB was carried out as described below. Fraction of Nos. 125 to 140 in the chromatogram shown in Fig. 8 were collected and were neutralized to $\mathrm{pH} 3$ with Amberlite IR-120 ( $\mathrm{H}$-form). The resin removed by filtration and the filtrate was condensed under reduced pressure at $40^{\circ} \mathrm{C}$. To the condensed solution two volumes of 95\% alcohol were added. A gelatinous precipitate was obtained. The precipitate was collected by filtration through the cheese cloth and was in vacuo over silica gel at $50^{\circ} \mathrm{C}$. The dried matter was dissolved in water and was precipitated by addition of alcohol. The procedure was repeated several times. Then the gelatinous matter was treated with absolute alcohol and ether, successively, and was dried in vacuo over silica gel. Fraction IB was

9) W. Heri, N. Neukom and H. Deuel, Helv. Chim. Acta 44, 1945 (1961)

10) A. W. Devor, J. Am. Chem. Soc., 72, 2008 (1950). 


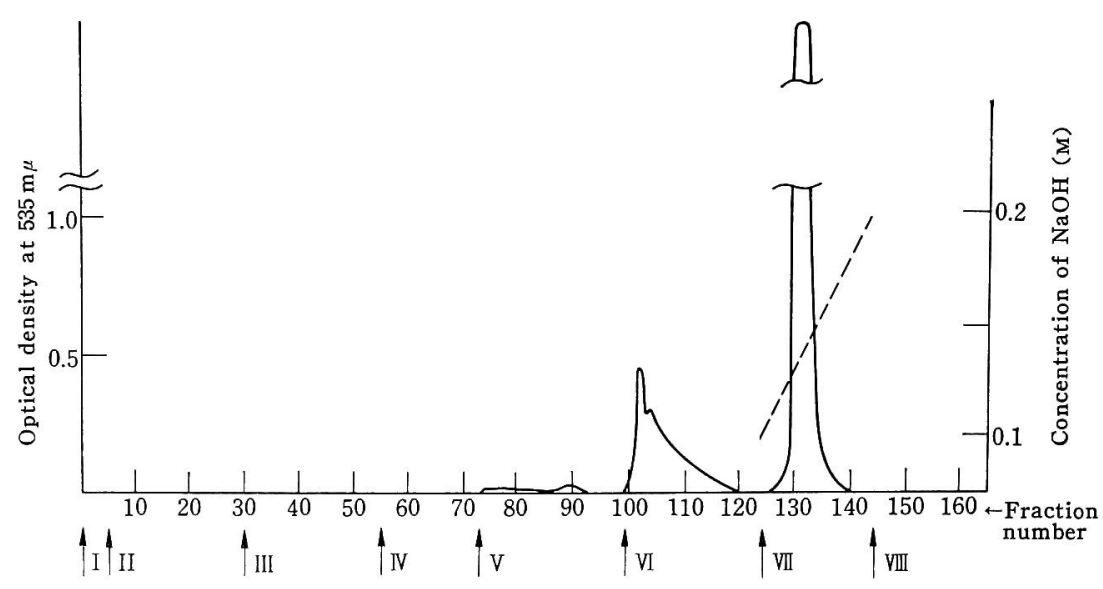

FIG. 8. Ion-exchange Chromatogram of Fraction I on DEAE-cellulose Column.

Eluting agent: I, $0.05 \mathrm{M} \mathrm{NaH}_{2} \mathrm{PO}_{4} ;$ II, $0.1 \mathrm{M} \quad \mathrm{NaH}_{2} \mathrm{PO}_{4} ;$ III, $0.2 \mathrm{M} \mathrm{NaH} \mathrm{NO}_{4} ;$ IV, $0.3 \mathrm{M}$ $\mathrm{NaH}_{2} \mathrm{PO}_{4} ; \mathrm{V}, 0.45 \mathrm{M} \mathrm{NaH}_{2} \mathrm{PO}_{4} ; \mathrm{VI}, 0.6 \mathrm{M} \mathrm{NaH} \mathrm{PO}_{4}$; VII, linear gradient elution with 0.1 to $0.2 \mathrm{M} \mathrm{NaOH}$; VIII, $0.5 \mathrm{M} \mathrm{NaOH}$.

-: Dische's test; --.: Change of concentration of $\mathrm{NaOH}$

obtained as white powder. Fraction IB behaved as homogeneous electrophoretically in EDTA solution as Fig. 9. As seen in Fig. 9, a peak retaining at the original position was observed. Electrophoresis of Fraction IB was carried out in closed system, and the part corresponding to the peak was pipetted out and was hydrolyzed. The reducing activity could not be detected on the hydrolyzate. Therefore, it was considered that the peak was caused by so called "anomalous phenomenon".

Since Fraction IB was confirmed to be homogeneous electrophoretically, measurement of optical rotation and determination of me-

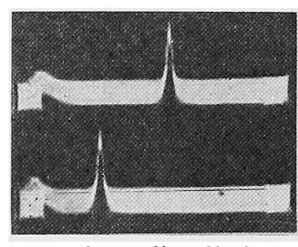

Ascending limb

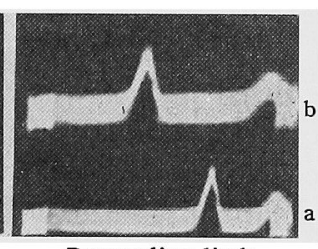

Descending limb
FIG. 9. Electrophoretic Pattern of Fraction IB in 0.03 M EDTA Solution ( $\mathrm{pH}$ 6.8).

Time: a, 2100 sec.; b, 4080 sec.

Electric current: $3.6 \mathrm{~mA}$. thoxyl group were carried out. $[\alpha]_{\mathrm{D}}^{26}=+294.7$ (water, c, 0.264). Content of methoxyl group was trace. The value obtained here agreed to the value reported by Öno, ${ }^{1)}[\alpha]_{D}^{18}=+291.66$, on saponification product of water extract of oh-gyo-tye. As it is believed that high positive, $[\alpha]_{\mathrm{D}}$ value of pectic acid $\left(+236^{\circ} \sim+260^{\circ}\right)$ caused by $\alpha$-linkage of galacturonic acid residue, ${ }^{11)}$ such large value of $[\alpha]_{D}$ of Fraction IB $\left(+294.7^{\circ}\right)$ may suggest the presence of $\alpha *$ linkage. On the one hand, K. H. Meyer et al. ${ }^{12)}$ had proposed that glucose residues were joined by $\alpha$-linkage in starch from the fact that $[\alpha]_{\mathrm{D}}\left(+216^{\circ}\right)$ measured on several kinds of starch were agreed with $[\alpha]_{D}\left(+230^{\circ}\right)$ for $\alpha-1 \rightarrow 4$ linkage calculated from $[\alpha]_{\mathrm{D}}$ of glucose and maltose according to Hudson's rule. ${ }^{181}$ Specific rotation for $\alpha-1 \rightarrow 4$ linkage of galacturonic acid residues $\left(+266^{\circ}\right)$ calculated from $[\alpha]_{\mathrm{D}}$ of mono- $\left(+55^{\circ * * * *}\right)$, di- $\left(+153^{\circ * *}\right)^{14\}}$ and tri-galacturonic acids $\left(+191^{\circ * * * * *}\right)^{14)}$ according

**** This value is that of the solution kept for 24 hours. ***** This matter, was prepared from pectic acid.

11) S. Luckett and F. Smith, J. Chem. Soc., 1940, 1106. 12) K. H. Meyer, H. Hopff and H. Mark, Ber., 62, 1103 (1929).

13) C.S. Hudson, J. Am. Chem. Soc., 31, 66 (1909). $14)$ R. L. Whistler and M. L. Wolfrom, "Methods in Car.
bohydrate Chemistry." Vol. 1, Academic Press, 1962, p. 309. 
to Meyer's calculating method, ${ }^{12)}$ was nearly equal to that of pectic acid and Fraction IB. Therefore, it may be presumed that galacturonic acid residues were joined by $\alpha$-linkage in Fraction IB.

The fact, content of methoxyl group of Fraction IB was trace, might be caused by saponification with sodium hydroxide solution during the chromatographic procedure.

Electrophoretic pattern of the mixture of Fraction IB, II and III was shown in Fig. 10. It was considered that Fraction II and III were similar to Fraction IB electrophoretically. As seen in Fig. 11, several peaks were observed in the electrophoretic pattern of the mixture of Fraction IB and IV However, further investigation on these fraction was not attempted because these were minor components. Fraction IB was used in the following experiments.

\section{Hydrolysis of Fraction IB}

One gram of Fraction IB was dissolved in $20 \mathrm{ml}$. of $85 \%$ formic acid and was hydrolyzated on the boiling bath for twenty four hours. Formic acid was removed from the reaction mixture by distillation under reduced

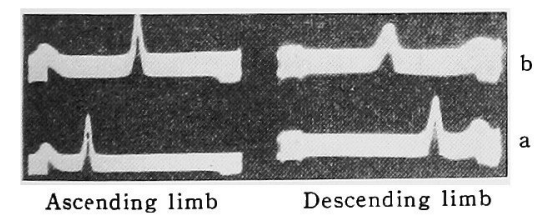

FIG. 10. Electrophoretic Pattern of Mixture of Fraction IB, II and III in $0.03 \mathrm{M}$ EDTA Solution (pH 6.8).

Time: a, 1800 sec.; b, 3000 sec.

Electric current: $3.55 \mathrm{~mA}$.

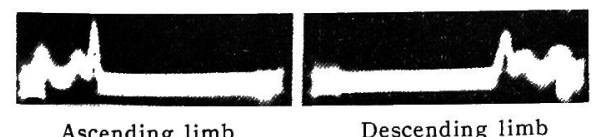

FIG. 11. Electrophoretic Pattern of Mixture of Fraction IB and IV in $0.03 \mathrm{M}$ EDTA Solution (pH 6.8).

Time: $1200 \mathrm{sec}$; $\quad$ Electrie current: $3.55 \mathrm{~mA}$. pressure at $50^{\circ} \mathrm{C}$. To the residue $50 \mathrm{ml}$. of $1 \mathrm{~N}$ sulfuric acid was added and the mixture was heated on boiling bath for eight hours. The $\mathrm{pH}$ value of the reaction mixture was adjusted to 6 by addition of balium carbonate powder. Precipitate of barium sulfate was removed by filtration and the filtrate was deionized by treatment with Amberlite IR-120 (H-form). The de-ionized solution was lyophilized. The hydrolyzate of Fraction IB was obtained.

\section{Chromatography of the hydrolyzate}

Thin-layer chromatogram of the hydrolyzate obtained as described above, was shown in Fig. 12. Not only the spot due to galacturonic acid, but a faint spot was observed. Paper chromatogram of the hydrolyzate was shown in Fig. 13. It may be considered that the faint spot, observed on the thin-layer chromatogram, was due to a pentose, probably arabinose, from color and position of the spot. The presence of galacturonic acid was reconfirmed by Khym and Doherty's chromato-

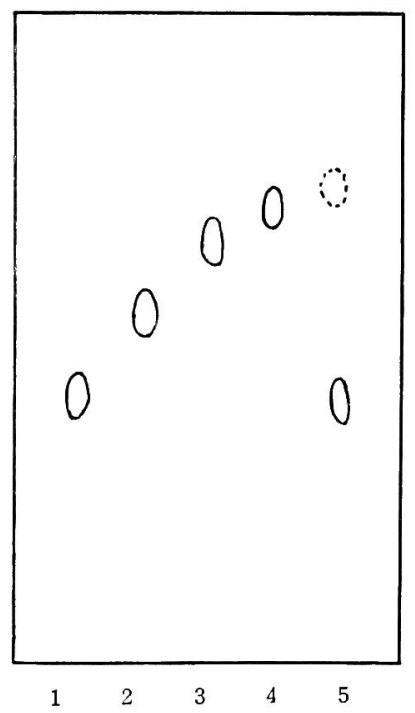

FIG. 12. Thin-layer Chromatogram of the Hydrolyzate of Fraction IB.

1, galacturonic acid; 2, glucuronic acid; 3, galactose; 4, sample (the hydrolyzate of Fraction IB)

Color reagent: $10 \%$ sulfuric acid solution. 


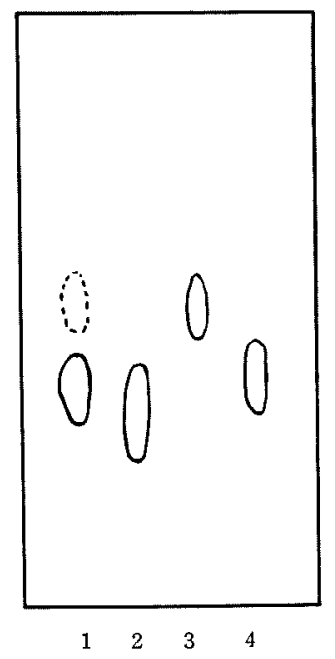

FIG. 13. Paper Chromatogram of the Hydrolyzate of Fraction IB.

1, hydrolyzate Fraction IB; 2 , galacturonic acid; 3 , arabinose; 4 , glucose.

Color reagent: Aniline hydrogen phthalate.

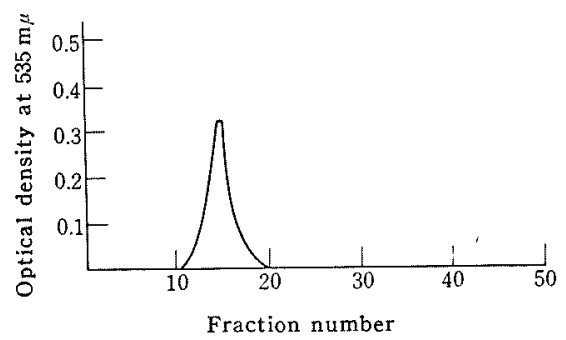

FIG. 14. Ion-exchange Chromatogram of Uronic Acid in the Hydrolyzate of Fraction IB.

graphic method. ${ }^{15)}$ As shown in Fig. 14, only one peak due to galacturonic acid in comparison to the chromatogram of standard material, was found. In this procedure, presence of neutral sugars could not be detected. Therefore, it was considered that Fraction IB mainly consisted of galacturonic acid. These results agreed with the result obtained by Ono, ${ }^{11}$ that the content of uronic acid was calculated to be $90.33 \%$ as galacturonic acid anhydride.

15) J. X. Khym and D.C. Doherty, J. Am. Chem. Soc., 74, 3199 (1952).

\section{Viscosity measurement}

Relation between concentration of Fraction IB $(c)$, relative viscosity $\left(\eta_{\mathrm{rel}}\right)$ and reduced viscosity $\left(\eta_{\mathrm{sp}} / c\right)$ is listed in Table II. With the decreasing concentrations of Fraction IB in solutions, the reduced viscosity of the solution increased. These phenomena have been widely recognized in measurement of viscosity of polyelectrolyte and have been usually interpreted as the result of a change in the shape from the spherical to the stretched rod due to the increasing of expansion power between dissociating group with decreasing of concentration of polyelectrolyte. Therefore, it may be considered that Fraction IB is a linear polyelectrolyte.

In such cases as above, Fuoss and Strauss ${ }^{16 !}$ proposed an empilical equation as below

$$
\eta_{\mathrm{sp}} / c=A /(1-B \sqrt{c})
$$

where $\eta_{\text {sp }}$ is specific viscosity, $A$ is a constant corresponding to the intrinsic viscosity, and $B$ is also a constant which represents interac-

TABLE II. VISCOSITY OF FRACTION IB

\begin{tabular}{|c|c|c|c|}
\hline \multirow[t]{2}{*}{ Solvents } & $\begin{array}{l}\text { Concentration } \\
\text { of Fraction IB } \\
(\mathrm{g} . / 100 \mathrm{ml})\end{array}$ & $\eta_{\mathrm{rel}}$ & $\eta_{\mathrm{sp} / \mathrm{c}}$ \\
\hline & 0.1 & 7.2 & 62 \\
\hline \multirow[t]{2}{*}{ Water } & 0.05 & 4.7 & 74 \\
\hline & 0.025 & 3.0 & 80 \\
\hline $0.1 \mathrm{~N} \mathrm{NaCl}$ & 0.05 & 1.7 & 14 \\
\hline
\end{tabular}

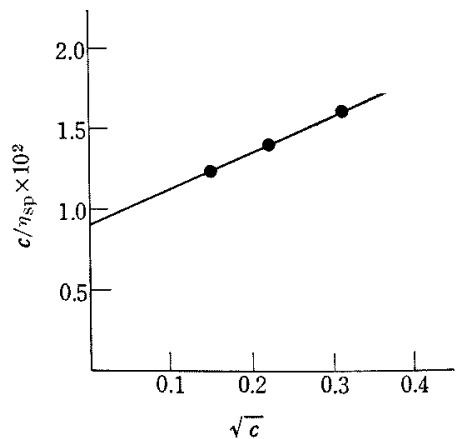

FIG. 15. $\left(\eta_{\mathrm{sp}} / c\right)^{-1}-\sqrt{c}$ Curve of Fraction IB.

16) R. M. Fuoss and U.P. Strauss, J. Polym. Sci., 3, 607 (1948). 
tion between the high and the low molecular ions formed by dissociation of the polyelectrolyte. As supposed from the equation, plotting $\left(\eta_{\mathrm{sp}} / c\right)^{-1}$ against $\sqrt{c}, A$ can be obtained as reciprocal value of $\left(\eta_{\mathrm{sp}} / c\right)^{-1}$ when $c$ is extrapolated to zero. The $\left(\eta_{\mathrm{sp}} / c\right)^{-1}-\sqrt{c}$ curve for Fraction IB is shown in Fig. 15 and intrinsic viscosity of Fraction IB is estimated to be 111 from this figure.

\section{Periodate oxidation}

For determination of the position of hydroxyl group in galacturonic acid residue which linked to I-position of adjointing the galacturonic acid residue, periodate oxidation of Fraction IB was carried out. Of the glycosidic linkages between galacturonic acid residues, the following, $1 \rightarrow 2,1 \rightarrow 3$ and $1 \rightarrow 4$ linkages may be considered.

When Fraction IB was oxidized with pe- riodate, the molar ratio of galacturonic acid residue to periodate consumption may be expected to be about 1 in cases of $1 \rightarrow 2$ and $1 \rightarrow 4$ linkages, and to be a large value, as $n / 4$ ( $n$ says number of galacturonic acid residue in Fraction IB), in case of $1 \rightarrow 3$ linkage. In the studies of citrus pectin, Levene and $\mathrm{Kreider}^{17}$ oxidized the periodate oxidation product with bromine, and detected tartaric acid in the hydrolyzate of the resulted substance. They concluded that the citrus pectin consisted of $1 \rightarrow 4$ linkage of galacturonic acids. When the procedure was applied to Fraction IB, the formation of following substances may be expected according to the kinds of glycosidic linkage of galacturonic acid residue; tartronic and formyl glycollic acids from $1 \rightarrow 2$ linkage, galacturonic acid from $1 \rightarrow 3$ linkage, and tartaric and glyoxilic acids from $1 \rightarrow 4$

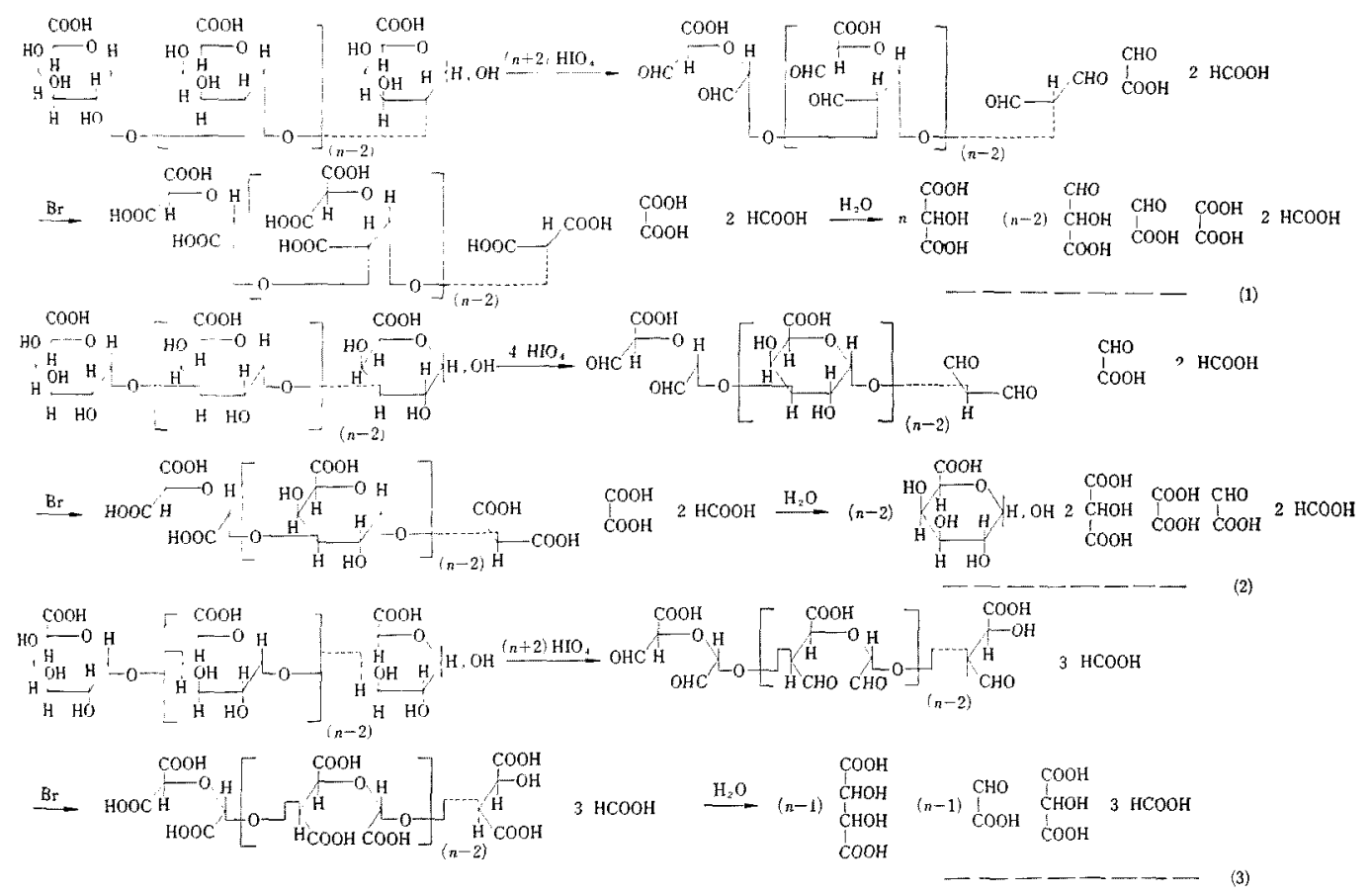

Scheme

17) P.A. Levene and L.C. Kreider, f. Biol. Chem., 120, 591 (1937). 
linkage. These relationships are shown in Scheme.

To $5 \mathrm{ml}$. of solution containing $13.2 \mathrm{mg}$. of Fraction IB, $56 \mathrm{ml}$. of $0.01 \mathrm{M}$ sodium periodate solution ( $\mathrm{pH}$ 3.6) was added and was kept at room temperature. Relation between the reaction time and consumption of periodate was shown in Fig. 16. After about seventy hours, consumption of periodate became constant and the mole of periodate consumption was equal to that of galacturonic acid residue. The formation of formic acid in the reaction was found to be very small quantity.

One hundred milli-grams of Fraction IB was dissolved in $30 \mathrm{ml}$. of the solution containing $300 \mathrm{mg}$. of periodic acid, and it was adjusted to $\mathrm{pH} 3.6$ by addition of sodium hydroxide solution. The solution was kept at room temperature. After seventy hours, the reaction mixture was neutralized with saturated strontium hydroxide solution and strontium carbonate powder. Iodic acid resulted from the reaction and excess periodic acid were precipitated as strontium salts by this procedure. The precipitate was removed by filtration. To the filtrate $1 \mathrm{ml}$. of bromine and $1 \mathrm{~g}$. of strontium carbonate powder were added and the solution was kept at $5^{\circ} \mathrm{C}$ for forty-eight hours. After bromine was removed by aeration, the reaction mixture was added to $6 \mathrm{ml}$. of $6 \mathrm{~N}$ sulfuric acid. After bromine

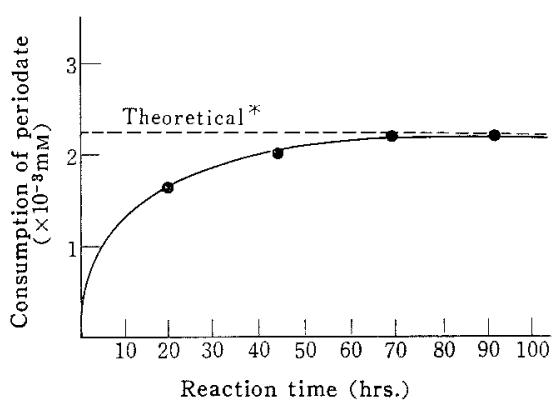

FIG. 16. Periodate Consumption with Fraction IB.

* The theoretical value is the value expecting from the assumption that Fraction IB consists of $1 \rightarrow 4$ linkage of galacturonic acid.

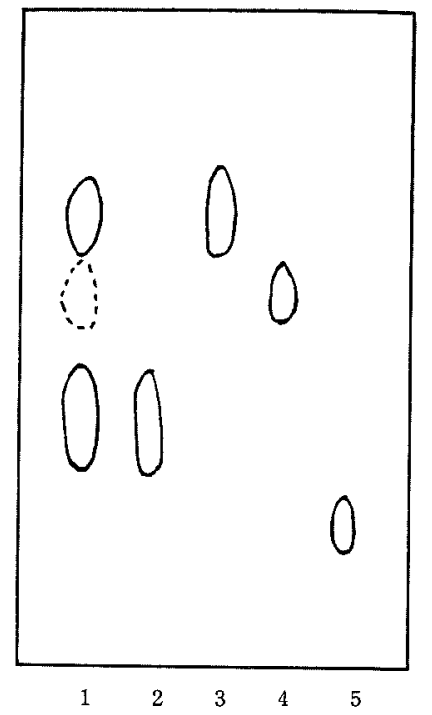

FIG. 17. Paper Chromatogram of the Reaction Product of Fraction IB.

1, sample; 2 , tartaric acid; 3 , glyoxylic acid; 4 , tartronic acid; 5 , galacturonic acid.

Color reagent: brom phenol blue solution.

was removed by aeration again, silver carbonate was added to the solution until foaming is not be seen. Precipitate was removed by filtration. After de-ionization with Amberlite IR-120 (H-form), the filtrate was hydrolyzed for thirteen hours. The hydrolyzate was neutralyzed by barium carbonate and precipitate was removed by filtration. The filtrate was condensed under reduced pressure at $40^{\circ} \mathrm{C}$ after treatment with Amberlite IR-120 (H-form). Paper chromatogram of the condensed solution was shown in Fig. 17. Two strong spots and one weak spot are observed in this figure. It may be considered that the two strong spots were due to tartaric and glyoxylic acids, respectively, and the weak spot was due to tartronic acid. The presence of galacturonic acid in the condensed solution could not be found on the chromatogram. Dische's test" for galacturonic acid was also negative in the condensed solution. Above mentioned results are agreed to results which 
re expected from the pathway (3) in Scheme. press their sincere thanks to Prof. K. Honda Therefore, it may be considered that Frac- for his kind guidance throughout this work. ion IB has a linear structure consisted of They are also grateful to Dr. D. Yonezawa, $\rightarrow 4$ glycosidic linkage of D-galacturonic acid, laboratory of food chemistry, for supplies of robably, $\alpha$-linkage, namely, Fraction IB was facilities for electrophoretic experiment, and ilassified to pectic acid. ${ }^{18)}$

Acknowledgement. The authors wish to exfor Mr. T. Mineshita, laboratory of biophysical chemistry, for his kind assistance in viscosity 18) Z.I. Kertesz, G. L. Baker, G. H. Joseph. H. H. Mattern measurements. They are further indebted to and A.G. Olsen, Chem. Eng. News, 22, 105 (1944). Mr. Z. Ikuta for his assistance. 